Políticas de vivienda

\title{
Política de vivienda y gestión de suelo urbano. Casos de Corea, Colombia y Perú (1990-2015)
}

Policy of Housing and Management of Urban Land. Cases of South Korea, Colombia and Peru (1990-2015)

Política de vivenda e gestão de solo urbano. Casos da Coreia, a Colômbia e o Peru (1990-2015)

\author{
Julio Calderón Cockburn ${ }^{*}$
}

Recibido: 13 de marzo de 2018

Aprobado: 26 de julio de 2018

Doi: http://dx.doi.org/10.12804/revistas.urosario.edu.co/territorios/a.6608

Para citar este artículo:

Calderón Cockburn J. (2019). Política de vivienda y gestión de suelo urbano. Casos de Corea, Colombia y Perú (1990-2015). Territorios (40), 201-226. Doi: http://dx.doi.org/10.12804/revistas.urosario.edu.co/ territorios/a.6608

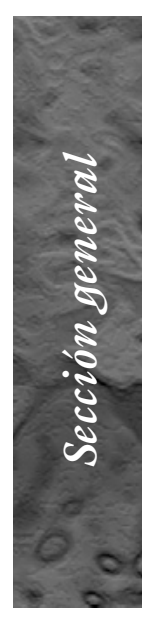

* Doctor, Sobresaliente, por la UNMSM de Lima. Magister, con honores, por la FLACSO de México y $\mathrm{Li}$ cenciado en Sociología por la PUCP de Lima. Consultor Independiente. Correo electrónicocockburnjulio@ gmail.com ORCID: http:// orcid.org/0000-00023623-3020 
Palabras clave

Politica habitacional, gestión del suelo, mercado inmobiliario del suelo.

Keywords

Housing policy, urban land management, real estate markets.

Palavras-chave

Politica habitacional, gestão do solo, mercado imobiliário do solo.

territarias 40

\section{RESUMEN}

Bajo un análisis comparativo de los casos de Colombia, Perú y Corea del Sur, se relaciona el rol del Estado con el mercado y se resalta la importancia de la gestión del suelo urbano y los programas de vivienda. Basado en la revisión de la bibliografía, se concluye que, aunque esos países han atravesado por procesos de liberalización y privatización desde la década de 1990, difieren en su esquema institucional de atención a la vivienda y gestión del suelo: un Estado desarrollador y planificador que promueve asociaciones público/privadas (Corea), otro que combina mecanismos de subsidio con gestión del suelo (Colombia) y otro en el que impera el libre mercado (Perú).

\section{ABSTRACT}

Under a comparative analysis of the cases of Colombia, Peru and South Korea, I center on the role of the state in housing policies in each of these countries, especially in relation to the market, highlighting the importance of land management. Based on the review of the bibliography, one concludes that though these countries have crossed for processes of liberalization and privatization from the decade of 1990, they differ in his institutional scheme of attention to the housing and urban land management: a state developer and planner who promotes public-private-partnership (Korea), another one that combines mechanisms of subsidy with management of land (Colombia) and another one in which there reigns the free market (Peru).

\section{RESUMO}

Sob uma análise comparativa dos casos da Colômbia, o Peru e a Coreia do Sul, se relaciona o rol do Estado com o mercado, ressaltando a importância da gestão do solo urbano e os programas de vivenda. Baseado na revisão da bibliografia, conclui-se que, ainda que esses países têm atravessado por processos de liberalização e privatização desde a década de 1990, diferem em seu esquema institucional de atenção à vivenda e gestão do solo: um Estado desenvolvedor e planificador que promove associações público/privada (Coreia), outro que combina mecanismos de subsídio com gestão do solo (Colômbia) e outro em que impera o livre mercado (Peru). 


\section{Introducción}

Aunque puedan existir diversas definiciones sobre vivienda social, en buena cuenta se trata de una política pública en la cual el Estado, de diversas maneras, pone en el bolsillo un dinero para que las familias se conviertan en demanda solvente. Originalmente concebida al servicio de la clase trabajadora, con el paso del tiempo y por razones sociales y de promoción de la actividad económica ( $\mathrm{y}$ constructora en particular), la vivienda social atiende a la clase media y a los pobres, en tanto los ricos y los muy pobres quedan de lado en razón de sus ingresos (muchos o muy pocos) y ahorros (muchos o inexistentes). Por medio de esta intervención, y de otras referidas al sector inmobiliario, el Estado, según Bourdieu (2002), construye doblemente el mercado de vivienda, tanto la oferta como la demanda, mediante dispositivos legales y administrativos (incluidos planes urbanísticos), subsidios y créditos.

En 1990-2015 en el mundo y en América Latina ha predominado la aplicación de políticas de libre mercado, en algunos casos combinadas con propuestas (neo) desarrollistas, insertas en la globalización de la economía. El papel regulador del Estado ha observado transformaciones y en las nuevas políticas urbanas predomina un rasgo privatizador. Las políticas de vivienda social se han basado en el subsidio a la demanda (modelo ahorro, bono y crédito), por el cual el Estado pone un subsidio al servicio de desarrolladores privados. Es tal el predominio de esta tendencia, que puede hacer olvidar la época del Estado constructor, el cual adquiría tierra, desarrollaba emprendimientos contratando a constructores privados e implementaba mecanismos financieros para la demanda. A su vez, puede olvidarse que el modelo de articulación público-privado con bajo riesgo a los desarrolladores no es el único modo que se aplica. En Brasil y Colombia se desarrollan e implementan instrumentos de gestión urbana que buscan incidir en los mercados de suelo bajo consideraciones de uso en función social y distinguiendo el derecho de propiedad del derecho de edificabilidad (Smolka \& Furtado, 2014). Estos esfuerzos no constituyen una novedad en el nivel mundial y existe una tradición de su aplicación en ciudades norteamericanas, europeas y asiáticas.

Este artículo aborda comparativamente tres casos de políticas de vivienda social nueva, sin entrar al abordaje de los programas de renovación urbana o de mejoramiento y regularización ${ }^{1}$. En Corea del Sur (en adelante Corea) existe una fuerte intervención de un Estado desarrollista. En el caso de Colombia, se aplica una política que combina los mecanismos financieros con intervenciones en el mercado de suelo y se reconoce la función social de la propiedad. En el Perú la política es abiertamente proclive al libre mercado. El estudio analiza las políticas públicas de vivienda social únicamente en relación con la gestión del suelo urbano, buscando establecer una conexión entre ambas variables. Por lo tanto, se abordan de manera lateral otras variables como los modelos financieros
${ }^{1}$ Por esta razón, el análisis no se detiene en la famosa titulación de tierras en el Perú. Al respecto, ver Calderón (2013). territarias 40 203 
aplicados, las políticas macroeconómicas, las ideologías específicas que sustentan estas políticas, entre otros. Las preguntas del estudio son: ¡cuáles han sido los principales elementos institucionales, económicos y políticos de las políticas públicas que han permitido atender las necesidades de suelo para vivienda social?

\section{Metodología}

El presente artículo es el resultado de un estudio realizado para el Programa de visita de becarios del Korean Research Institute of Human Settlements (KRIHS) de Corea del Sur y el Banco Interamericano de Desarrollo (BID) en el 2015.

El estudio asume una perspectiva comparativa, cuyas virtudes han sido subrayadas por la sociología. Solo se puede entender lo específico de una ciudad, siguiendo a Weber, si se sabe lo que le falta de otras, y el método comparativo permite ver las diferencias y es útil en la búsqueda de las explicaciones (Burke, 1987). En el campo específico de los estudios comparativos sobre vivienda, las mayores contribuciones han sido para las sociedades occidentales industrializadas, especialmente las europeas, por lo que su alcance es limitado para esta reflexión. Dichas sociedades experimentaron Estados de bienestar, ausentes en Colombia y Perú. En el mundo industrializado, Kemeny y Lowe (1995) han distinguido aproximaciones universalistas, particularistas (culturalistas) y de medio rango; aunque Stephens (2014) ha apuntado que dichos autores en realidad recurren a la vivienda para contribuir a la teoría sobre la relación entre vivienda y (estado de) bienestar.

El criterio de elección de los países (Corea, Colombia y Perú) proviene de dos demandas. Una es institucional, expresada en la iniciativa coreana (Calderón, 2017). La otra demanda es de carácter teórico. Aunque resulte comprensible estimar co- $^{-}$ mo exagerada una comparación entre la política de vivienda de la séptima economía del mundo (Corea), y Perú y Colombia, los cuales ajustadamente han ingresado al club de los países de ingresos medios, hay otros aspectos que podrían palear estas diferencias. Históricamente, hace solo unos 60 años, de acuerdo con indicadores económicos convencionales, Corea era más pobre que Perú y Colombia, y sus problemas de vivienda eran mayores, a juzgar por el hecho que Seúl, su capital, tenía un porcentaje mayor de población en asentamientos precarios que Bogotá o Lima. El estudio quiere prestar atención a las políticas públicas al interior de las estructuras sociales y económicas en que se despliegan. Entre 1960-1970 los tres países intentaron procesos de industrialización, pero solo Corea lo logró, incluso enfrentando la oposición del Fondo Monetario Internacional. Perú y Colombia vieron frustrados sus procesos de Industrialización por Sustitución de Importaciones (ISI) y, en la década de 1990, asumieron políticas de libre mercado, lo cual, en buena cuenta, promovió la desindustrialización de lo alcanzado.

Las políticas públicas de vivienda actuales, ciertamente, difieren en aspectos 
sustanciales. Por ejemplo, la inversión pública coreana en adquisición de tierra rural y provisión de infraestructura para urbanizarla requiere de fondos que los países latinoamericanos no poseen. Sin embargo, hay otros aspectos que consideramos sustanciales y que no se pueden explicar por la riqueza de unos países. Por ejemplo, la opción por un Estado de corte neo-desarrollista, o uno de corte neoliberal, debe ser asociado con las decisiones de las elites políticas y su capacidad de autonomía; al igual que el componente ideológico y modo de discurso que sustenta las políticas (Kemeny, 1992)2.

El eje interpretativo responde a un constructo teórico centrado en la política de vivienda y la gestión del suelo. Esta conexión, debe atender a las consideraciones de la estructura económica y social de cada país, el sistema de vivienda y la ideología. En su dinámica interna, se encuentra asociada con los medios e instrumentos reguladores, la negociación entre el Estado y agentes económicos como propietarios de tierras, desarrolladores inmobiliarios y capital financiero, la distribución entre rentas urbanas y ganancias entre los agentes, entre otros. Estas variables serán objeto de seguimiento en los tres casos y constituirán las variables explicativas. El constructo establece una graduación entre los casos a partir de la capacidad estatal reguladora. Corea presenta una mayor variedad y solidez en la aplicación de instrumentos de gestión del suelo para proveer vivienda social. Según este criterio, Colombia, y en realidad la experiencia de Bogotá, se ubica en una posición intermedia, y Perú constituye un caso en el que predomina el libre mercado en la política (y en la ideología).

Las fuentes de información en las que se basó el estudio han sido secundarias, y han consistido en revisión bibliográfica de estudios sobre vivienda social y de información estadística. Complementariamente, se aplicaron algunas entrevistas a funcionarios y expertos de los tres países considerados $^{3}$. El estudio se realizó en el lapso de 2 meses, incluyendo una corta estadía en Corea del Sur. Este corto tiempo explica que en la revisión bibliográfica se hayan priorizado algunas ciudades dentro de los países considerados.

El periodo de análisis en que se estudian los casos tiene dos fases. En la primera, se revisan, a grandes rasgos, los antecedentes de las políticas de vivienda y gestión del suelo en cada país, desde su constitución hasta fines de la década de 1980. Debe indicarse que, aunque Perú y Colombia inician más temprano sus políticas hacia las décadas de 1940, la experiencia coreana, iniciada en la década de 1960 , resulta más densa y variada por el modo en que el Estado establece sus relaciones con los agentes privados (propietarios y desarrolladores), favoreciéndolos. En cambio, Perú y Colombia combinan un 'dejar hacer' a los desarrolladores con intentos de Estado constructor y permisibilidad a los asentamientos precarios. La segunda fase, la cual considera desde la década de 1990 en adelante, muestra que, en Colombia y Perú, aunque con diferencias en los mecanismos de gestión del suelo y en el discurso, se opta
${ }^{2}$ Kemeny (1992) considera la ideología como un aspecto central, no derivado, de las formaciones sociales y la vía en que las instituciones están constituidas, sostenidas y cambiadas. La ideología, y el modo del discurso, provee la motivación para la acción y cumple un papel importante y decisivo al determinar el tipo de sociedad que se quiere desarrollar. Existen diversas ideologias dominantes para la legitimación de las sociedades industriales de las cuales se ocupa.

${ }^{3}$ Las entrevistas realizadas fueron al Dr. Jung, HeeNam (KRIHS), Laura Lozada, Gislene Pereyra, Juan Pinilla, Maria Cristina Rojas, Rodolfo Santa María (Fondo Mi Vivienda, Perú) y Guillermo Fernández (Programa de Generación del Suelo urbano, Perí).

territorios 40 205 
por políticas neoliberales; mientras que en Corea se afirma un Estado neo desarrollista que incrementa la participación pública en la provisión de vivienda.

\section{Los casos}

En perspectiva histórica, seis décadas atrás, Corea tenía un desarrollo económico muy pobre y su economía era superada tanto por la peruana como la colombiana (ver Producto Interno Bruto - PIB - per cápita en la tabla 1). Solo hacia 1990 el PIB per cápita coreano superará al de Colombia y al de Perú y, a 2010, ya era cuatro veces más.

Tabla 1. PIB per cápita. 1960-2010 (USD)

\begin{tabular}{|l|l|l|l|l|l|}
\hline País & 1960 & 1980 & 1990 & 2000 & 2010 \\
\hline Corea & 1,226 & 4,114 & 8,704 & 14,998 & 21,701 \\
\hline Colombia & 2,497 & 4,257 & 4,826 & 5,375 & 7,063 \\
\hline Perú & 2,969 & 4,262 & 3,008 & 3,737 & 5,774 \\
\hline
\end{tabular}

Fuente: Roser, M. Human Development Index (HDI). En "Economic Growth".

En cuanto al Ingreso Nacional per cápita, a 2014 el coreano era tres veces más que el colombiano y el peruano (tabla 2 ).

Tabla 2. Ingreso Nacional per cápita 19902014 (USD)

\begin{tabular}{|l|c|c|c|}
\hline \multicolumn{1}{|c|}{ País } & $\mathbf{1 9 9 0}$ & $\mathbf{2 0 1 0}$ & $\mathbf{2 0 1 4}$ \\
\hline Corea & 7,518 & 29,824 & 36,511 \\
\hline Colombia & 4,876 & 10,805 & 13,846 \\
\hline Perú & 3,415 & 9,62 & 12,194 \\
\hline
\end{tabular}

\section{territarias 40}

Fuente: Fondo Monetario Internacional World Economic Outlook, Washington.
La explicación corta es que Corea se industrializó de manera planificada, y $\mathrm{Co}^{-}$ lombia y Perú no, pues no pasaron de frustrados intentos de industrialización por sustitución de importaciones. La economía coreana pasó de una manufactura de gran demanda de mano de obra (1960), continuando con una industria pesada y química (1970) y, a partir del 2000, con parques de alta tecnología (Jung, 2014). A su vez, el peso de la agricultura se redujo entre 1975 y 1999 gracias a una política articulada y planificada desde el Estado (Cuellar, 2012).

Aunque Corea gozó de factores geopolíticos favorables, no debe subestimarse el empuje del Estado (neo) desarrollista que se distinguió de las recomendaciones de los organismos multilaterales. Según Stiglitz (1997), la opción coreana representó un quiebre con la supuesta antinomia entre los paradigmas tradicionales del desarrollo económico, uno centrado en los mercados y otro en el Estado y la planificación. En realidad, no fue este un camino propio y creativo. Ha Joon Chang (2004), luego de estudiar el camino seguido por los países industrializados concluyó que, en algún momento, los Estados implementaron políticas proteccionistas y que, luego de alcanzar una fase de desarrollo productivo, se convirtieron en guardianes del libre mercado. De ahí la metáfora que los países que ascienden por la escalera del desarrollo, una vez que trepan a la cúspide, se apresuran en patear la escalera para evitar que otros también asciendan (Cuellar, 2012). Colombia y Perú no se industrializaron y 
hacia 1990 asumieron una economía de libre mercado, abierta a la globalización de la economía. Hoy se mueven entre la estabilidad macroeconómica y la atracción de la inversión extranjera, sin un horizonte definido.

Corea, Colombia y Perú atravesaron en la década de 1950 procesos de urbanización acelerada. La inmigración a las ciudades de la población rural generó asentamientos precarios y procesos de ocupación del suelo informales. En los sesenta, un $30 \%$ de la población de Seúl, unas 750 mil personas, empujada por la Guerra de Corea, habitaba asentamientos precarios (Kim Soo, 2014). En Bogotá, el $45 \%$ de su población en 1970 vivía en este tipo de asentamientos abarcando el $40 \%$ del stock de viviendas (Duhau, 1998) y, en Lima, en 1970, el $25 \%$ de la población (Calderón, 2016). Frente a esta realidad, en los tres países los gobiernos respectivos establecieron diversas políticas de vivienda que desarrollaron distintas maneras de gestionar el suelo urbano.

\subsection{Caso de Corea}

\subsubsection{Antecedentes}

El Estado coreano, tras la liberación de la colonización japonesa (1910-1945), estableció su primer Plan Quinquenal de Desarrollo 1962-1966, orientando la inversión pública hacia la industrialización del país. Hubo débil proclividad de la política pública a alentar el consumo interno y se careció de una inversión significativa en vivienda. El Estado, en consecuencia, creó una serie de mecanismos institucionales y legales para promover la intervención de desarrolladores privados en la provisión de vivienda. Entre ellas, la ley de planeamiento urbano de 1962, la cual permitió el re-zoneamiento de tierra, y la ley de expropiación de tierras que facilitó reclutar tierra cruda para industrias e infraestructura urbana (La Grange \& Jung, 2004).

Por entonces, las tierras de expansión urbana estaban en manos de propietarios beneficiarios de la reforma agraria de 1949, siendo que la antigua clase terrateniente había sido desplazada a la industria. La propiedad privada de la tierra había sido introducida bajo la dominación japonesa, siendo que hacia 1910 era de propiedad del Estado (Dinastía Choson). La Constitución de 1948 reconoció el derecho de propiedad y a arrendar, y los propietarios debían ejercer sus derechos conforme al bienestar público general (La Grange \& Jung, 2004). En 1945 de 2225571 hectáreas, un $37 \%$ eran trabajadas por los propietarios, un $63 \%$, por arrendatarios y un $2,6 \%$ por peones. Tras la reforma agraria que combinó confiscación y distribución gravosa (se pagó a los propietarios), unas 953000 unidades fueron distribuidas a pequeños propietarios (a razón de 3 hectáreas por fundo) y, a 1960, solo restaba un $11 \%$ de arrendatarios ( $\mathrm{Su}, 2015)$.

El sistema de vivienda estuvo articulado a la gestión del suelo. En 1966, la Land Compartmentalization and Rearrengement Projects Act permitió el uso de métodos de replanteo buscando acuerdos territarias 40 207

Política de vivienda y gestión de suelo urbano. Casos de Corea, Colombia y Perú (1990-2015) 
con los propietarios de tierras, reorganizando el suelo dentro de los límites de un Proyecto, y asegurando tierra pública (Kim, 2013). Ese mismo año, la ley de reajuste permitió a los propietarios de tierras periurbanas involucrarse en el desarrollo urbano, recibiendo a cambio dinero en efectivo o tierra servida en proporción a su aporte. En 1967 se creó el Housing \& Commercial Bank, en 1968 la Korea National Housing Corporation (KNHC), en 1978 la Korea Land Development Corporation (KLDC), la cual permitió luego el desarrollo masivo de tierra para el sector público; y, en 1980, la Land Development Promotion (Jung, 2014; Kim KJ, 2014).

Entre 1962-1971 se construyeron en Corea 866000 unidades de viviendas, un $12,5 \%$ contribución del sector público (108250). Entre 1972-1981, de unas 1870000 unidades el aporte público creció a un $39 \%$. En total, entre 1962-1981, de 2736000 viviendas producidas, el sector público aportó 837550 (30,6\%) (Park, 2013). Los conjuntos habitacionales públicos fueron puestos a la venta y no para alquiler, dejando de lado a la gente de menores ingresos que no podían acceder al crédito (La Grange \& Jung, 2004).

A inicios de 1980 , un $13 \%$ de la población de Seúl vivía en asentamientos precarios (Kim Soo, 2014), poco más de un millón de habitantes, muchos menos que el $30 \%$ detectado hacia la década de 1960. Entre 1983 y 1989 los Join Redevelopment Projects permitieron al Estado remplazar los asentamientos precarios por torres de departamentos, siendo que unos
67 asentamientos fueron borrados en Seúl y unos 150000 inquilinos involuntariamente desplazados (Kim Soo, 2014). Los propietarios de viviendas no autorizadas recibieron una sustancial compensación y los inquilinos no pudieron encontrar relocalización adecuada e iniciarían luchas por vivienda adecuada. Esta situación llevaría al Estado a asignar para vivienda pública un $17 \%$ de las nuevas habilitaciones (Kim, 2014).

La política pública consideró medidas de expropiación de tierras, pagando el Estado a tasas por debajo del mercado para proveer parques industriales, Nuevas Ciudades (New Towns) y otras necesidades de desarrollo urbano. El Reajuste de Tierras, usado entre los sesenta y los setenta, hizo posible el desarrollo de tierra servida sin costo para el Estado, y en una vía que no perjudicaba a los propietarios porque muchas de las ganancias de estos esquemas los beneficiaban (La Grange \& Jung, 2013). Se desarrolló cerca del $50 \%$ del área construida en Seúl, el 30\% en Kwang-Ju, el $40 \%$ en Pusan, etc. No obstante, en 1984 los reajustes de tierras fueron prohibidos porque beneficiaban únicamente a los propietarios privados de la tierra, debido a los incrementos de los precios de la tierra y las ganancias del desarrollo.

\subsubsection{Politica de vivienda y suelo}

En 1989 se da inicio a la primera política de vivienda que podría llamarse tal, de acuerdo con criterios internacionales. Se trató de la vivienda pública permanente 
de alquiler (Kim Soo, 2014). Para entonces, la economía se había industrializado en productos basados en el conocimiento, el ingreso per cápita había alcanzado USD 8590 , existía una clase media en ascenso $\mathrm{y}$, al igual que en el resto del mundo, se habían dado pasos a una liberación de la economía, políticas de desregulación, apertura de mercados, privatización de bancos comerciales; aunque ciertas políticas intervencionistas permanecieron. Por otro lado, se produjo un proceso de democratización impulsado por movimientos sociales de la clase media y la clase trabajadora (protestas de 1986 y 1987). En 1992 la ciudadanía eligió al primer gobierno civil no militar, se instauró una democracia representativa y se generaron movimientos ciudadanos, incluida la Korean Coalition for Housing Rights and Citizens for Decent Housing (La Grange \& Jung, 2013; Park, 2013; Kim, 2014).

Una política de vivienda suscrita por las principales fuerzas políticas permitió una fuerte institucionalidad, ejecución de planes urbanos y empresas públicas con manejo empresarial de la inversión pública y privada (Korea Land and Housing Corporation, desde el 2009, Korea Hihgway Corporation y Korea Water Resources Corporation). El "Plan de construcción de dos millones de viviendas 1988-1992", de 1987 (Kim, s.f.), permitió edificar 850000 viviendas por el sector público y 1150000 viviendas por el sector privado (Park, 2013). Para los pobres urbanos, el sector público construyó 250000 viviendas de alquiler permanente, con dimensiones de 20 a $36 \mathrm{~m}^{2}$; y para la potencial clase media unas 600000 viviendas por medio de la National House Fund.

Los resultados fueron impresionantes: el ratio de oferta de vivienda, el cual mide el total de hogares contra el total de vivienda, pasó de $72,4 \%$ en 1990 al 96,2\% en el 2000, y a 112,9\% en el 2010 (Park, 2013). En Corea hay más viviendas que hogares. Se pasó de viviendas únicas (un $90 \%$ en 1980) a departamentos (un $60 \%$ en 2010), se aumentó el espacio per cápita en metros cuadrados, el porcentaje de número de cuartos por hogar, el número de unidades por cada 1000 personas, el servicio de inodoro al $97 \%$ y el suministro de agua potable al 93,7\%. La tasa de propietarios de los hogares, a su vez, pasó de $49,9 \%$ en 1990 a $54,2 \%$ en 2010 , los alquileres de $8,2 \%$ a $20,1 \%$ y los Chonse 4 bajaron de $27,8 \%$ en 1990 a $21,7 \%$ en 2010 (Park, 2013).

Las autoridades se inspiraron en las New Town inglesas, ciudades planeadas, desarrolladas y construidas como remedio al hacinamiento y la congestión, bajo los Public Management Development (PMD). Las New Towns, debido a que no había tierra vacante dentro de las áreas urbanas, se ubicaron en las afueras de las ciudades, en un radio de 20 a 25 kilómetros del distrito central y de negocios. Las New Towns contaban con vivienda, espacios públicos, actividades comerciales, oficinas públicas, entre otros. En Seúl, entre 1989-1996, se construyeron 5 con unas 292000 unidades de vivienda en 5013 hectáreas (tabla 3 ). Se trató de "ciudades satélites" de alta
${ }^{4}$ El sistema Chonse es una forma de inquilinato que consiste en entregar la mitad del precio total de la $v i$ vienda al propietario y vivir en esta por un promedio de 2 años, al término del cual el inquilino pide la devolución del dinero depositado. En ese lapso, el propietario invierte dicho monto.

territarias 40 209 
densidad (23500 personas por $\mathrm{km}^{2}$ ), con edificios multifamiliares, y que dependían de Seúl en términos de empleo, educación, comercio y actividades culturales.

Tabla 3. Nuevas ciudades en Área Metropolitana de Seúl

\begin{tabular}{|l|l|l|}
\hline Nuevas Ciudades & \multicolumn{1}{|c|}{ Hectáreas } & \multicolumn{1}{c|}{ Población } \\
\hline Ilsan & 1574 & 276000 \\
\hline Jungdong & 545 & 166000 \\
\hline Pyongchon & 511 & 168000 \\
\hline Bundang & 1964 & 390000 \\
\hline Sanbon & 420 & 168000 \\
\hline
\end{tabular}

Fuente: Jung, 2014.

En cuanto a la gestión del suelo, la ley de promoción del desarrollo de la tierra residencial (1979) y la ley de uso y gestión de la tierra nacional (Kim, s.f.), permitieron desarrollos residenciales en gran escala por medio de la compra pública de tierras y desarrollo, en remplazo de los Proyectos de Reajuste de Tierras y el método de redesarrollo urbano aplicados entre 1960-1980.

El esquema de desarrollo de la tierra empezaba con la planificación, la determinación del lugar (zona agrícola) en que se harían los proyectos, proceso en que las municipalidades intervinieron desde 1994 , y cuyos planes de desarrollo fueron elaborados por la Korea Land Development Corporation (KLDC) y otras entidades. Por medio de los PMD, el Estado adquiría grandes extensiones de tierras a los propietarios privados a precios tasados a un valor más bajo que los precios de mercado. Desde 1980 hasta inicios del siglo XXI, unos 489 $\mathrm{km}^{2}$ fueron provistos por el PMD, $43 \%$ por medio de la Korean Land Corporation (KLC, desde 1998), 14\% por la KNHC, $39 \%$ por gobiernos locales, entre otros ( $\mathrm{La}$ Grange \& Jung, 2004). A pesar de que el Estado tuvo extensos poderes de expropiación, la mayoría de la tierra $(95 \%)$ fue adquirida por mutuos acuerdos entre las autoridades públicas y los propietarios de tierras, así como compensaciones por pérdidas acordes al Código Civil (La Grange \& Jung, 2004). Entre 1982 y 2000 , el Estado adquirió $328935000 \mathrm{~m}^{2}$ para vivienda, siendo los mayores años de adquisición 1989, 1990, 1991, 1995 y 1996, en que se adquirió el 52,6\% del total.

El Estado, con base en el plan de desarrollo que asigna usos del suelo (parámetros, diseño de distribución de tierras, tamaño de las manzanas), habilita la tierra y pone la infraestructura. Una vez que la tierra ha sido subdividida, partida y servida, el Estado conserva una parte y vende otra a desarrolladores privados para la construcción de vecindarios a precios controlados, lo cual generó fondos considerables para los gobiernos y ayudó a atender las necesidades de vivienda (La Grange \& Jung, 2004; La Grange \& Jung, 2013; Kim, s.f.). El Estado, al decidir la cantidad de tierra para sus propios proyectos de vivienda $y$ las que venderá a constructores privados, obtiene ingresos de lo que antes formaban parte de las rentas y ganancias de los propietarios. territarias 40 
Las tierras para vivienda pública en alquiler son vendidas cerca del $70 \%$ a $95 \%$ de los costos de construcción. Para los desarrolladores privados los precios por la tierra fueron avaluados más bajo que el precio de mercado (La Grange \& Jung, 2004), a cambio de que produzcan un número de unidades dentro de un periodo acordado y un $25 \%$ de unidades de alquiler social a precios controlados. El restante $75 \%$ de las viviendas eran vendidas $\mathrm{y}$, al respecto, los controles de precio han sido relajados en los últimos tiempos. En una New Town se tienen precios de USD 200000 por un departamento de $59 \mathrm{~m}^{2}\left(3389,8\right.$ USD $\left./ \mathrm{m}^{2}\right)$ y de USD 300000 por otro de $84 \mathrm{~m}^{2}$ (USD $3571,4 / \mathrm{m}^{2}$ ) (Pereira, comunicación personal, 2015). El gobierno ha establecido un plan 2007-2017 para ofertar 2,6 millones de unidades de vivienda en alquiler de largo término para reforzar el rol del sector público en mejoramiento de bienestar en vivienda (Park, 2013).

En estos procesos, especialmente desde las medidas privatizadoras expedidas hacia 1990, desarrolladores privados han aparecido y participan activamente en el desarrollo urbano y desarrollo de la tierra como lo hace la KLC (La Grange \& Jung, 2013), lo cual ha llevado a políticas cambiantes ${ }^{5}$.

En Corea, la urbanización se acompañó de la industrialización. La tasa de urbanización pasó de 37,0\% en 1960 a 90,9\% en el 2010 y la tasa de industrialización de $36,8 \%$ en 1963 a $92,8 \%$ en 2010 (Jung, 2014). El Estado ha conducido el desarrollo urbano ejerciendo el rol de promotor inmobiliario, articulando y coordinando a los diversos actores con intereses conflictivos (desarrolladores, gobiernos locales, propietarios de tierras, residentes) bajo criterios de planificación territorial. El crédito subsidiado, a diferencia de América Latina, no ha sido aplicado en gran escala debido a que el Estado ha usado el control de la oferta de la tierra y del costo de la vivienda para facilitar fondos para la construcción de viviendas. Aunque existan más viviendas que hogares, los problemas habitacionales siempre tienen formas de aparecer, sea con la propagación de los cubículos ilegales de vivienda (Gosiwons), el peso del alquiler en los hogares de bajos ingresos, la obsesión de la vivienda en propiedad (en 2010 había un $49,5 \%$ de propietarios en las grandes ciudades), el envejecimiento de la población y los proyectos de renovación urbana. Los asentamientos precarios se han reducido hasta casi su virtual desaparición. En 1987 en Seúl existían 204 asentamientos, con 84818 unidades, correspondiendo al $8,7 \%$ de todas las viviendas y conteniendo al $13 \%$ de la población (Kim, 2014), mientras que a 2011 se estimaba una población en 25000 hogares, unas 100 mil personas, el $1 \%$ de la población metropolitana (source: Gooryoung Mauel Policy Council Organization an Operation Plan, 2014).

\subsection{Caso de Colombia}

\subsubsection{Antecedentes}

En Colombia, al igual que en el resto de América Latina, en los inicios del siglo Xx
${ }^{5}$ Los controles de precios de las viviendas fueron eliminados en 1998 después de la crisis asiática de 1997y, en el 2000, se ha permitido al sector privado participaren $P M D$, aunque restringido al 49,9\% de accionariado, $y$ se re-autorizaron proyectos de reajuste de tierras. En 2001 un acta requirió pagos de justa compensación por las expropiaciones ( $\mathrm{La}$ Grange \& Jung, 2004). El sector público, al permitir una mayor participación de la empresa privada, ha reducido sus costos. territarias 40 211 
la provisión de vivienda estuvo a cargo de un mercado de rentistas urbanos o de urbanizadores de facto, en el que predominaba la vivienda en arriendo. Gradualmente, con la Ley 46/18, en 1918, y la adopción en 1942 de la planificación moderna, se desarrolla un enfoque 'viviendista' que buscaba incrementar la productividad del sector construcción y reducir los costos de edificación para que las personas pudieran financiar su adquisición (Fiqué, 2006).

Cevallos y Saldarriaga (2015) distinguen diversas fases en las políticas de vivienda en Colombia. La fase higienista (1918-1942), en la cual se crea el Instituto de Crédito Territorial (ICT), en 1939 (Decreto Ley 200), destinado a la construcción de viviendas higiénicas para la población rural y que, en 1942, abrió una sección de vivienda urbana; así como el Banco Central Hipotecario $(\mathrm{BCH})$ en 1938. La fase institucional 1942-1965 en que se dieron amplios dispositivos para atender la problemática de la vivienda, seguida por la fase de transición 1965-1972. Durante la fase de las corporaciones de ahorro y vivienda, 1972-1990, se aplica la Unidad de Poder Adquisitivo Constante, más conocida como UPAC, la cual canalizaba el ahorro de familias que deseaban comprar una vivienda. En la década de 1970, la UPAC, un sistema de captación de ahorro privado y financiación del sector construcción, impulsó más la actividad constructora y la convirtió en un sector líder de la inversión del capital financiero, e instrumento para el impulso y recesión de la economía.
Según el patrón de las políticas públicas en vivienda aplicadas en América Latina, instituciones como el ICT y el BCH fueron promotores públicos de vivienda, antes que un canal de crédito especializado en vivienda. Correspondería a la etapa hoy llamada del "Estado constructor", en la cual los gobiernos construían viviendas, otorgaban subsidios e implementaban una política financiera. El Instituto de Crédito Territorial (ICT) construyó 120 mil viviendas entre 1947 y 1991 y el Banco Central Hipotecario unas 14040 viviendas entre 1930 y 1991 (Torres, 2008).

En cuanto a la gestión de la tierra, las diferencias con la experiencia de Corea son ostensibles. La distribución de la tierra fue impulsada por las fuerzas del mercado, con débil regulación, y con un Estado que más bien ejerció influencia sobre los precios vía la determinación de las áreas que gozarían de los servicios y aquellas que serían excluidas (Fiqué, 2006). En el sistema se establecieron tres mercados de vivienda: en el plano formal, el mercado privado con las mejores tierras, el estatal con las tierras mediocres y el informal, de 'barrios piratas', promovidos por desarrolladores ilegales que ocupaban las peores tierras y en que los compradores autoconstruían sus viviendas (Camargo \& Hurtado, 2013).

Durante el proceso de urbanización, la participación del sector privado en construcción se incrementó a la vez que la oferta estatal decreció, y los precios por la tierra aumentaron. Las entidades públicas tuvieron que acudir a las peores y lejanas tierras suburbanas en busca de precios 
mínimos. Los ajustes de los precios trasladaban ganancias iniciales del constructor y promotor inmobiliario al propietario del suelo, lo que generó procesos alcistas ante cualquier reactivación de la demanda $\mathrm{y}$, por lo tanto, de la oferta de vivienda. Cualquier intento de cambiar las reglas del juego enfrentaba la oposición de grupos poderosos ligados a la construcción y la propiedad territorial urbana (Fiqué, 2006).

\subsubsection{Una politica de vivienda y suelo con dos modelos}

Hacia 1989 y 1990 la política de vivienda social se implementa bajo dos modelos: una mayor intervención de los gobiernos locales en los mercados de suelo y el subsidio público a la demanda para incentivar la inversión de los constructores en vivienda social, emulando el "modelo chileno".

El primer modelo (1989), desarrolla un esquema de vivienda orientado a los gobiernos locales con capacidad de intervenir en los mercados del suelo. La Ley de Reforma Urbana (9/89) estableció la prevalencia del interés público sobre la propiedad privada, reglamentó los planes de desarrollo municipales, los planes de renovación urbana (Ambrosi, 2011) y la declaratoria de desarrollo y construcción prioritarios para combatir la especulación y retención de terrenos (Maldonado \& Hurtado, 2013). El modelo tuvo un paréntesis a partir de 1990, aunque la Constitución Política de 1991 estableció el derecho a la vivienda condicionado (Artículo 5l) y la prevalencia del interés general sobre el particular, otorgando a la propiedad una función social que implicaba obligaciones (Ambrosi, 2011).

Esta ideología - modo de discurso de la política - se mantuvo a pesar de la aplicación de un modelo económico neoliberal. En 1996, el Ministerio de Desarrollo Económico (MDE) recordó las limitaciones del bien suelo que restringían la eficiencia del mercado como óptimo asignador de recursos: difícil aplicación del principio de homogeneidad (por la localización del suelo), no reproducible, operando en mercados segmentados y sin competencia perfecta. Consideraba que la libre disponibilidad del suelo era producida por la estructura de la ciudad, y no por los promotores privados, por lo cual “(se) puede valorizar un predio sin que su dueño haya retribuido a la sociedad por la obtención de este beneficio" (MDE, 1996, p. 78). Se consideraba que la promoción de una distribución equitativa de cargas y beneficios requería un Estado regulador, facilitador y garante del desarrollo económico y social, el cual debía "corregir las deficiencias provocadas por el mercado" (MDE, 1996, p. 83), aclarando que no se podía "concebir al Estado como la negación del mercado" (MDE, 1996, p. 75).

La Ley de Desarrollo del Territorio de 1997 (388/97) definió el ordenamiento como una función municipal, la distribución equitativa de las cargas y beneficios para financiar los costos del desarrollo urbano y dotó a las municipalidades de herramientas para la gestión del suelo. Estableció que los Planes de Ordenamiento territarias 40 213 
${ }^{6}$ La Ley 388/97 estableció la Vivienda de Interés Social (VIS) destinada a clase media y la Vivienda de Interés Prioritario (VIP) para sectores de menores ingresos, cuyo precio no podía superar por entonces los USD 14000.

\section{territarias 40} 214
Territorial (РОT) debían definir suelo para VIS y VIP ${ }^{6}$.

La legislación colombiana estableció cuatro tipos de instrumentos (Maldonado, 2012, 182-183):

- Reglamentación de usos del suelo, calificación o determinación de usos obligatorios de vis y sus porcentajes;

- Intervenciones directas de las autoridades públicas de manera exclusiva o en asociación con actores privados o comunitarios (bancos de tierras, adquisición del suelo, asociaciones públicoprivadas en macro-proyectos, gestión asociada, reajuste de tierras, reparto equitativo de cargas y beneficios, derecho de preferencia, control de precios del suelo);

- Inducción de comportamientos a los agentes privados para evitar la especulación (declaratoria de desarrollo prioritario sujeta a venta forzosa en subasta pública).

- Instrumentos financieros como participación en plusvalías que permitirían recuperar los incrementos en los precios del suelo (entre $30 \%$ y $50 \%$ ) producidos por cambios en las normas de clasificación, uso e intensidad del suelo.

El segundo modelo se generó en 1990, cuando un nuevo gobierno, al influjo de la liberalización y la privatización, decidió profundizar la apertura económica y desregulación, abriéndose un subsidio a la demanda, restringiendo la política edi- ficadora a sus aspectos financieros y congelando el esfuerzo de intervención en el mercado de suelo (Maldonado, 2012). Las instituciones precedentes (UPAC, ICT, $\mathrm{BCH}$ ) fueron dejadas de lado. Las Leyes 049/90 de 1990 y 3/91 de 1991 buscaban que los pobres accedieran al mercado mediante un Subsidio Familiar de Vivienda (SFV), y definieron los requerimientos de las soluciones (oferta), incluyendo los topes de precios de las viviendas a ser construidas. Se esperaba incorporar a las familias más pobres como demanda solvente de la promoción privada. Pero, en el caso de Bogotá, las familias más pobres $(20 \% \mathrm{del}$ total) no pudieron aportar el ahorro inicial ni pagar la cuota hipotecaria periódica del préstamo complementario. Por su parte, los bancos encontraban poco atractivo los préstamos para vivienda social (montos pequeños, costos administrativos mayores y riesgos altos). Era paradójico que las familias para calificar a los subsidios debían demostrar pobreza y para obtener crédito lo opuesto (Cuervo \& Jaramillo, 2009). En la búsqueda de la demanda, muchos promotores debieron reducir el tamaño de la vivienda y del terreno (casas de $32 \mathrm{~m}^{2}$ ).

El sistema de vivienda observó un mercado privado orientado a la clase media y alta y los esfuerzos públicos frenados; y el mercado de urbanizadores ilegales ('piratas') pudo ofrecer terrenos más amplios y constituirse en una mejor alternativa para el sector pobre. Entre 1993-1996 el costo del suelo aumentó hasta 3 veces en zonas aprovechables para proyectos de vivienda social, y unas 200 hectáreas se 
urbanizaron ilegalmente en la zona occidental de la ciudad de Bogotá (MDE, 1996). A 2001, los asentamientos precarios en Bogotá ocupaban el $23 \%$ del área urbana (715 654 ha), acogían al $22 \%$ de la población total (2 166939 habitantes) y contaban con 1533 barrios y 401285 predios (Torres, 2008).

A partir del siglo XXI, la política de vivienda combinó el subsidio a la demanda y la intervención municipal en la gestión del suelo urbano, en especial en la ciudad de Bogotá que se tomará como referente. El modelo de gestión del suelo fue objeto de la férrea oposición de los propietarios de tierras, quienes apelaron a la Corte Suprema de Justicia, cuestionaron los propios actos administrativos (Pinilla, 2013) y ejercieron presiones políticas; frenando la aplicación de algunos instrumentos como, por ejemplo, la declaratoria de desarrollo y construcción prioritaria o el derecho de preferencia (salvo para el caso de Usme en Bogotá). Debe indicarse que el poder político de los propietarios se encuentra en directa relación con su control monopólico de la tierra en expansión. Mientras en Cali, por ejemplo, existen pocos propietarios que presionan a las autoridades, en Bogotá existen propietarios con diversas extensiones. Sobre un total de 7241 hectáreas de suelo libre, un $23,6 \%$ pertenece a predios con menos de 3 hectáreas, un 17,6\% a áreas entre 10 y 30 hectáreas y solo 2 predios tienen áreas superiores a 300 hectáreas, el 7,6\% (Cevallos, 2013).

Entre los instrumentos aplicados se tuvo la expropiación y la contribución de valorización. La municipalidad de Bogotá, antes que localizar terrenos para VIS o para VIP, planteó en su POT que los nuevos desarrollos debían dejar un $15 \%$ del área para VIP y un $20 \%$ para VIS. La municipalidad de Bogotá desarrolló un banco de tierras por medio de Metrovivienda (MV), empresa creada en 1998. En una primera generación, MV compró suelo no urbanizado a los propietarios de tierras, mediante enajenación voluntaria o expropiación, y procedió a su urbanización/ habilitación y venta directa de manzanas urbanizadas a desarrolladores. Los constructores privados asumían los riesgos de construir y vender. Las familias adquirientes se financiaban por medio del subsidio, el crédito y recursos propios. Existió también una modalidad asociativa en que los propietarios de tierras habilitaban y comercializaban; y una de tercera generación que integraba a MV como gestor, al propietario del suelo como aportante, al sector privado como constructor y a la comunidad organizada (Ambrosi, 2011).

La evaluación de MV no ha sido muy satisfactoria. Entre 1993-2005 proveyó 11667 viviendas en Bogotá, el 1,67\% de las unidades producidas, mientras que los desarrollos ilegales proveyeron 441180 unidades de un total de 817000 viviendas construidas (54\%) (Ceballos, 2013). Por lo tanto, MV no impactó en el precio del suelo, el cual continuó siendo elevado y trasladado al comprador final. Entre otros problemas, hubo desajustes temporales entre el anuncio y la compra de las tierras, se invirtió en las dos primeras ciudadelas territarias 40 215 
más de 110 millones de dólares en 245 hectáreas y 18400 viviendas (11800 de ellas a precio inferior a USD 12500 ), pero con las ventas a los constructores solo se recuperó el $50 \%$ porque de otro modo no se hubiera podido construir vivienda de bajo precio. MV compró suelo a precio relativamente alto y tuvo también altos costos administrativos (Maldonado, 2012). Mientras algunos opinan que MV no puede controlar la dinámica de precios, otros adjudican las debilidades al hecho de que no se aplicara el conjunto de dispositivos existentes, especialmente los referidos a la captura de plusvalía (Cuervo \& Jaramillo, 2009).

Entre algunas propuestas de soluciones, la sugerencia que MV comercialice suelo no urbanizado y que el comprador asuma los costos de habilitación, la gestión asociada como eje del sistema urbano, la integración inmobiliaria, la cooperación entre stakeholdersy reajuste de tierras en el marco de planes parciales (Rojas \& Rave, 2013), adquirir suelo a cambio de las inversiones públicas en arterias, redes matrices, etcétera; descontar el mayor valor obtenido por el propietario de tierras con posterioridad para evitar el enriquecimiento sin causa justa (Maldonado, 2005).

La reglamentación de usos del suelo por medio de la designación de usos y porcentajes obligatorios para vivienda social ha sido aplicada desde el 2000. La preferencia de los planes a favorecer reservas para VIS (clase media, con precio tope de USD $40 \mathrm{mil}$ ), antes que a VIP (menores ingresos, con precio tope de USD 14 a
20 mil), y la posibilidad de trasladar terrenos a otros proyectos de la ciudad, ha permitido a los desarrolladores mantener la rentabilidad en los terrenos de mayor precio y evitar la mezcla social. Además, funcionarios municipales alegan que es importante mantener altos los valores del suelo en ciertas zonas para mantener un buen nivel de recaudación del impuesto predial (Maldonado, 2012).

La política de vivienda ha contrarrestado poco la informalidad urbana. De 3134114 viviendas producidas en Colombia entre 1993-2005, un 64,9\% fueron aportadas por el sector informal y un $35,1 \%$ por el sector formal. De este, menos del $50 \%$ (546522) fueron viviendas sociales y, de estas, solo 146845 de interés prioritario (VIP). En promedio, cada año se construyeron 30744 vis (clase media) y 11295 VIP (Henao, 2013). En Bogotá, entre 1993-2005 la mitad de las 404302 unidades fueron VIS, unas 204426 viviendas para la clase media (Cuervo \& Jaramillo, 2009; Maldonado, 2012). Unas 199876 viviendas fueron ofertadas libremente en el mercado $(49,4 \%)$. En forma paralela, aumentó la vivienda autoconstruida en relación con periodos precedentes, alcanzando un $44,2 \%$ de la producción total de la vivienda. Podría decirse que se había retrocedido en el objetivo central de lucha contra la ilegalidad (Cuervo \& Jaramillo, 2009).

A partir de la Ley del Plan de Desarrollo Urbano 2006-2010, el gobierno nacional decidió intervenir en la generación de suelo urbano por medio de los 
Macroproyectos de Interés Social Nacional (MISN). Para ello, estableció un patrimonio autónomo basado en un esquema fiduciario, puesto a licitación y adquirido por el banco FIDU Bogotá. La idea era promover la participación de propietarios de tierras y desarrolladores en operaciones conjuntas con el Estado. Como los MISN irrumpieron contra la figura de la descentralización colombiana, las municipalidades formularon una demanda ante la Corte Suprema de Justicia, la cual declaró inexequible la propuesta (Pinilla, comunicación persona, 2015).

Una segunda generación de macroproyectos (Ley 1469 de 2011) estableció que las decisiones administrativas y actuaciones urbanísticas se definirían de común acuerdo entre el gobierno nacional y las municipalidades. Un ejemplo de MISN ha sido Ciudad Verde, con 325 hectáreas y una construcción prevista de 42000 viviendas. Una promotora privada lideró el proyecto adquiriendo el terreno al sur-oeste de Bogotá y se conformó un fideicomiso englobando los terrenos. Se prevé $20 \mathrm{mil}$ viviendas VIP y unas 22000 VIS, a un costo promedio de 16000 a 17000 dólares (Moreno \& González, 2011). La provisión de infraestructura ha corrido por cuenta de la promotora (proyecto $100 \%$ privado), la cual ha asumido cargas (vías y redes internas) (Moreno \& González, 2011).

A partir de 2011, el gobierno colombiano estableció un plan para construir un millón de viviendas dignas, considerando 5,3 millones de hogares que no podían alcanzar el apoyo financiero, 4,9 millones de pobres y 1,2 millones de pobres extremos. De esta meta, 650 mil viviendas serían de interés social (VIS) y 350 mil de interés prioritario (VIP). A 2012 se había producido 192000 viviendas VIS, un $37 \%$ de la meta para esta categoría de vivienda. También la política busca producir 100000 viviendas gratuitas para personas pobres y vulnerables, de las cuales se habían licitado 62 mil a noviembre de 2012 . Los macro-proyectos (MISN) se diseñaron en número de 11, en 1949 hectáreas para 135954 unidades (Henao, 2013), y han sido concluidos a la actualidad.

\subsection{Caso de Perú}

\subsubsection{Antecedentes}

Hasta mediados del siglo xx, en el Perú la vivienda era atendida por los mecanismos del mercado, formales e informales, mediante urbanizaciones para la clase media y tugurios en alquiler para los pobres. La intervención pública fue nula hasta entrada la década de 1920 en la que los gobiernos municipales empezaron a establecer una serie de regulaciones, con la oposición de las compañías urbanizadoras. En la década de 1930 se desarrollaron unos cuantos Barrios Obreros y Barrios Fiscales en Lima y Callao. Habría que esperar hasta 1948 cuando, bajo los principios del urbanismo moderno tardío, se iniciaron las políticas públicas de vivienda con la creación de la Corporación Nacional de la Vivienda (CNV). Desarrolladas fundamentalmente en Lima y Callao, las viviendas se insertan territarias 40 217 
en el modelo de las Unidades Vecinales, aplicando arquitectónicamente un "modernismo sin modernidad" (Kahatt, 2015, p. 51). Por el escaso número de unidades habitacionales públicas construidas, su efecto en el conjunto del sistema de vivienda fue pobre. Las urbanizaciones privadas siguieron habilitando tierras agrícolas para la clase media, y los pobres, venidos del campo, invadieron tierras públicas y constituyeron barriadas.

Este reducido esfuerzo público en vivienda fue cortado por un gobierno liberal (1956-1962) que, a la letra, consideraba que no era al sector público el que debía producir viviendas, sino el mercado. La solución liberal fue otorgar subsidios (el sistema mutual importado de los Estados Unidos de América) e infraestructura (capital fijo) a los desarrolladores privados, para que urbanizaran para la clase media, y programas de titulación, autoconstrucción de viviendas y provisión de servicios para los pobres, siendo importante la Ley de Barrios Marginales de 1961 (Calderón, 2016).

El sistema de vivienda se fundamentó en el esquema tierra privada para clase media y tierra pública para los pobres. La política pública de vivienda desarrolló una serie de instituciones financieras (las mutuales, el Banco de la Vivienda y el Banco Central Hipotecario, creado desde 1928) y se creó la Junta Nacional de la Vivienda (JNV), en 1962, en remplazo de la CNV. Pocos esfuerzos se desarrollaron en términos de gestión de suelo urbano, pues predominó el criterio de dejar el asunto a los mecanismos del mercado. Solo hubo una preocupación estatal por asegurar la propiedad pública de los terrenos improductivos periféricos, hacia donde se canalizaría la demanda de suelo de los sectores de bajos ingresos. Esta política resultaría conveniente a los grandes propietarios de tierras que habían devenido en urbanizadores. En 1955 unos 65 de ellos controlaban toda el área de expansión de la ciudad de Lima, unas 31456 hectáreas, y 11 monopolizaban el $52 \%$ de estas (Calderón, 2016). El "banco natural” de tierra pública en la periferia, establecido por la Constitución de 1933 sobre las tierras improductivas, fue utilizado para canalizar el proceso de ocupación popular. El propio Plan de Desarrollo Metropolitano de Lima de 1968 reservó estas tierras públicas.

Este esquema de distribución de la tierra fue alterado cuando la reforma agraria de 1969 amenazó con la expropiación a los propietarios privados, lo cual fue respondido por estos con el desarrollo de mercados ilegales. De todos modos, la reforma agraria cambió la estructura de tenencia de las tierras de expansión urbana. En Lima, el Censo Agropecuario de 1994 mostró que los pequeños propietarios agrarios tenían 21801 hectáreas (a un promedio de 1,7 hectárea por agricultor) y las comunidades campesinas unas 20264 hectáreas (Calderón, 1998).

En 1969 se creó el Ministerio de Vivienda y, en 1979, el Fondo Nacional de la Vivienda (FONAVI) el cual, a partir de la contribución de patrones y trabajadores, pretendió atender la demanda de vivienda 
desembarazando de dicho costo al Estado. A pesar de miles de viviendas construidas, la obra pública nunca fue pródiga. Entre 1920-1970 se había producido en Lima, ciudad para la cual se cuenta con información, unas 38434 viviendas (Ludeña, 2004) y, entre 1971 y 1990, unas 47808 viviendas en todo el país para clase media, y para los pobres urbanos unos 197528 lotes en la periferia (Ministerio de Vivienda, 1980). Mientras tanto, el sistema de vivienda se había constituido según el patrón de urbanizaciones privadas para la clase media y tierra improductiva para barriadas en la periferia, en las cuales los pobres debían levantar sus viviendas. En Lima, en 1984, un $32 \%$ de la población vivía en barriadas, 1600000 personas (Calderón, 2016, 246).

\subsubsection{La politica de vivienda y el modelo de libre mercado}

Desde 1990, el de Perú es un caso en que el libre mercado ha sido la opción adoptada en política de vivienda por gobiernos neoliberales, a diferencia de Colombia donde, como se ha visto, se plantearon dos modelos. El modelo de libre mercado en Perú promovió una economía extractiva primaria, y tras el "ajuste económico" de 1990, siguió una ola de privatizaciones y de eliminación, hacia 1992, del Ministerio de Vivienda, el Banco Central Hipotecario, el Banco de la Vivienda del Perú, el Fondo Nacional de la Vivienda (FONAVI), el sistema Mutual, entre otros. La política neoliberal en general, y de vivienda en particular, asumió un discurso ideológico privatista, antiestatista y de libre mercado el cual, por su intensidad, podría ser comparado con el chileno (Hidalgo, et al., 2016).

La aplicación del modelo neoliberal en vivienda ha atravesado dos etapas. Una primera del "mercado como solución" (19901998) y otra de subsidios financieros a la demanda (2001-2018), con una mínima o casi nula política de gestión pública de suelo urbano, planificación en general e intervención municipal. Es curioso constatar que, mientras hacia 1990 Colombia buscaba emular el modelo ABC chileno implantado en 1980, los policy makers peruanos buscaban emular al de Chile de 1975 , el del "mercado como solución". En 1993 la Constitución restringió el papel económico del Estado, la ley de expropiación eliminó las consideraciones de uso social, la reforma tributaria municipal (DL 776) eliminó la contribución de mejoras y los impuestos a los terrenos sin construir y, en 1995, la "Ley de Tierras" (Ley 26505) liberalizó el mercado de suelo. Sin subsidio público, el sector inmobiliario privado solo pudo construir en 1997 unas 6 mil unidades para la clase media alta (Calderón, 2009). La informalidad urbana explotó y, entre 1993 y 1998, del incremento total de población en Lima un $64 \%$ pasaron a vivir en una barriada (Calderón, 2016).

El subsidio financiero a la demanda, atendiendo la presión de los constructores, se autorizó entre 1997-1998, y el Estado inyectó USD 600 millones a la banca privada. El conjunto de la política se estructuró y se ha mantenido en manos del gobierno nacional sin participación de las territarias 40 219 
${ }^{7}$ El Programa Techo Propio, creado en el 2002 tiene como modalidades Vivienda Nueva (AVN), Construcción en Sitio Propio (CSP) y Mejoramiento de Vivienda (MV).

\section{tersitarias 40}

municipalidades. La política de vivienda se puso al servicio de la productividad de la economía. El modelo despegó a partir de 2002, tras una serie de arreglos institucionales (creación del Ministerio de Vivienda en 2002, Plan Nacional de Vivienda 2006-2015, modificación de normas de densidades y usos del suelo), mayores subsidios y aumento de los topes máximos de las viviendas, pasando estos de 30 a $35 \mathrm{mil}$ dólares (Calderón, 2009). No obstante, la provisión y gestión de la tierra urbana continuó siendo dejada al mercado.

La política de vivienda social, inspirada en el modelo $\mathrm{ABC}$, terminó favoreciendo a la demanda de la clase media, la cual obtuvo un $80 \%$ del monto invertido (Fondo Mi Vivienda, luego "Nuevo Crédito Mi Vivienda" NCMV). Entre enero de 2006 y junio de 2012 la clase media recibió USD 1060 559,876 (monto per cápita USD $30,187)$, unas 8 veces más que el programa para los pobres, Techo Propio, con USD 133998968 (monto per cápita USD 5732) (Calderón, 2014) ${ }^{7}$. En ese lapso, el Estado solo invirtió un $30 \%$ de lo que había estipulado en el Plan Nacional de Vivienda 2006-2015 (USD 3503 millones en total). Aunque en el corto plazo la política aumentó la oferta de vivienda, redujo los precios de las viviendas y auspició el crecimiento vertical en algunos distritos de las principales ciudades, a la larga contribuyó a la subida de los precios del suelo. Los sectores de menores ingresos se beneficiaron poco de la inversión y de la política.
Tabla 4. Número de Créditos otorgados por la política de vivienda 1999-2013

\begin{tabular}{|c|c|c|c|c|}
\hline Años & FMV & AVN & CSP & MV \\
\hline 1999 & 143 & & & \\
\hline 2000 & 405 & & & \\
\hline 2001 & 1442 & & & \\
\hline 2002 & 3611 & & & \\
\hline 2003 & 6166 & 3709 & & \\
\hline 2004 & 7960 & 1992 & 27 & \\
\hline 2005 & 9205 & 702 & 32 & \\
\hline 2006 & 5540 & 625 & 15 & 9 \\
\hline 2007 & 3123 & 2262 & 762 & 163 \\
\hline 2008 & 2994 & 2077 & 10029 & 922 \\
\hline 2009 & 3527 & 4085 & 22807 & 1753 \\
\hline 2010 & 6436 & 5144 & 12807 & 543 \\
\hline 2011 & 8888 & 6014 & 6062 & 388 \\
\hline 2012 & 10133 & 4498 & 12957 & 405 \\
\hline 2013 & 12064 & 3414 & 20493 & 8 \\
\hline & 81637 & 34522 & 85991 & 4191 \\
\hline
\end{tabular}

Fuente: elaboración propia con base en información en página web del Ministerio de Vivienda, Construcción y Saneamiento del Perú.

FMV: Fondo Mi Vivienda, AVN: Vivienda Nueva, CSP: Construcción en Sitio Propio y MV: Mejoramiento de Vivienda.

La falla de la política de vivienda tiene explicaciones diversas, pero hay coincidencia en el argumento del incremento de los precios de la tierra urbana, producto del boom de la construcción 2006-2012. La política de vivienda en Perú deja manos 
libres a los desarrolladores para acudir a los mercados de tierras, sin que realmente existan instrumentos de gestión del suelo. En Lima, los precios por la tierra urbana entre 2010 y 2013 pasaron de USD 1,192/ $\mathrm{m}^{2}$ a USD $1474 / \mathrm{m}^{2}$ (Castillo, 2014), lo cual hizo perder efervescencia a la actividad inmobiliaria en 2014. Los subsidios a la vivienda estimularon la demanda por terrenos por parte de los desarrolladores, lo cual llevó a que los propietarios elevaran sus precios y, de esta manera, el precio del suelo carcomía el subsidio. La existencia de tres mercados formales de demanda de suelo (privado, NCMV/ clase media y Techo Propio) incide en las apropiaciones de renta de la tierra, en tanto los promotores y constructores encuentran nichos de rentabilidad en los dos primeros mercados (Calderón, 2015). Por eso, hay "escasez" de suelo para vivienda social de menores ingresos, pero no para las otras modalidades.

Los desarrolladores privados consideran que la solución a la vivienda social es que el Estado aumente el monto de los subsidios a la demanda, con lo cual se pueda cubrir los mayores precios por la tierra. Es reducido el monto de la inversión pública que, al año 2015 era de 175 millones de dólares estadounidenses, frente a Colombia con 908 millones o, más aún, Chile con 2390 millones (Aramburú, 2016). También los desarrolladores han propuesto que el Estado oferte tierras públicas por debajo de su precio de mercado. Los agentes privados circunscriben la agenda pública a la política de vivienda y su ideología privatista (Estado facilitador).
No ubican en la agenda la discusión misma de la necesidad de una política de gestión de suelo, la cual es rechazada por principio.

En ausencia de planificación, y resistencia a generar una política y ley de suelo, la propuesta pública se ha orientado en función del "banco de tierras" de propiedad estatal. Diversos dispositivos se han abocado a la venta de tierra pública. $\mathrm{Al}$ año 2012 funcionarios del Ministerio de Vivienda anunciaban que existían 570000 hectáreas de tierra pública improductiva en 18 ciudades y se requería construir 500000 unidades de vivienda (Romero, 2012). En 2012 se creó el Programa de Generación de Suelo Urbano, PGSU (D.S. 003-2012-VIVIENDA). Sin embargo, la mayoría de estos terrenos requieren habilitación urbana y saneamiento legal. A pesar de estos tibios esfuerzos, no resulta clara la voluntad gubernamental por avanzar hacia mecanismos de gestión del suelo urbano y el eje sigue siendo el mecanismo financiero de subsidio a la demanda. Mientras tanto, el déficit de vivienda se incrementa. A 2007 las cifras oficiales en Lima mostraban que un $48 \%$ de la población vivía en la informalidad y que, entre 2002 y 2007, las barriadas se habían duplicado ocupando áreas de riesgo (MVCS, 2014).

\section{Conclusiones}

Este estudio comparativo empezó interrogándose por los principales elementos institucionales, económicos y políticos de las políticas públicas que han permitido atender las necesidades de suelo para vivienda territarias 40

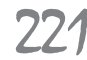


social. Bajo un eje interpretativo centrado en la política de vivienda y la gestión del suelo, ha atendido los medios e instrumentos reguladores, la negociación entre el Estado y agentes económicos y la distribución entre rentas urbanas y ganancias. Se ha buscado ubicar esta comparación en las consideraciones de la estructura económica y social de cada país, el sistema de vivienda y la ideología.

El periodo 1990-2015 corresponde a diversos proyectos de modernización en los países observados, específicamente neodesarrollistas y neoliberales que nunca se imponen en forma pura, sino inmersos en contextos políticos-institucionales que han sido significativamente moldeados por disposiciones regulatorias, prácticas institucionalizadas y compromisos políticos (Brenner \& Theodore, 2017).

El caso Corea se destaca en la comparación no solo por haber alcanzado un estadio de industrialización, sino por haber plasmado una política de vivienda la cual, suscrita por las principales fuerzas políticas, ingresó a la agenda pública y estableció una continuidad con los antecedentes institucionales previos a la década de 1990. Esta es una diferencia con los casos de Colombia y Perú en los que, a partir de esa década, se produce una ruptura con la institucionalidad anterior, Es paradójico constatar que los cambios de política en Corea mantuvieron y ampliaron las instituciones, pero produjeron una modificación entre los agentes al reducir costos al Estado e incrementar los riesgos de los desarrolladores inmobiliarios.
En Colombia y Perú ocurrió algo diferente. Las instituciones fueron eliminadas radicalmente, pero el Estado continuó, como lo había hecho desde la década de 1940, asumiendo costos (y cargas) al servicio (y beneficios) de los desarrolladores.

Los tres casos permiten observar diferencias respecto a las alianzas público/ privadas. En Corea, por medio de compra públicas de tierras y habilitación, se ha desarrollado un modelo mixto en que ganan ambos, resultando que el Estado, al asumir un rol de promotor inmobiliario y planificador, recupera su inversión por medio de rentas del suelo y ganancias que antes eran apropiadas por desarrolladores. Y se ha logrado atender en gran parte la demanda de vivienda. Mediante el control de la oferta de tierra y del costo de la vivienda el Estado no ha requerido otorgar subsidios e implementar mecanismos financieros. En Colombia, por medio de dos modelos que conviven, los instrumentos de gestión del suelo apuntan hacia alianzas público/ privadas desde el criterio de reparto de cargas y beneficios. Las dificultades de esta propuesta han sido puestas de relieve por la bibliografía consultada, especialmente en el caso de la experiencia municipal en Bogotá, y existen esfuerzos empresariales privados por asumir ciertas cargas de la urbanización. En Perú las políticas de vivienda no promueven alianzas público/ privadas, el Estado se autoadjudica un rol facilitador, desdeña las propuestas de urbanización asociada por el temor con no favorecer a los desarrolladores privados y frenar el modelo de crecimiento económico. 
El libre mercado manda y el Estado solo es invocado si va a proporcionar subsidios o tierra pública barata.

La ideología, en la acepción de un modo de discurso y motivación para la acción, se distingue en los tres casos. En Corea, un Estado (neo) desarrollista plantea un riesgo compartido público y privado, y alianzas en las cuales los propietarios de tierras mantienen una posición subordinada. Los casos de Colombia y de Perú deben resaltarse por tratarse de países que comparten una misma matriz de configuración histórico-estructural, una vena conservadora y regímenes neoliberales. Sin embargo, en Colombia hay un discurso proclive a la planificación, el ordenamiento territorial y la función social de la propiedad, los cuales se encuentran absolutamente ausentes en el caso peruano. En Colombia, en el contexto de un marco de disputas políticas, se plantea un Estado regulador y facilitador que no opone el Estado al mercado, y que reconoce deficiencias del mercado. El Perú, en su ideología y en su marco legal, es un país de libre mercado, menor injerencia estatal y ausencia de municipalidades. La diferencia entre ambos, aunque esto ameritaría un estudio detenido, parece encontrarse en las elites y sus posturas ante el urbanismo.

Las diferencias anotadas inciden en los sistemas de vivienda, al interior de los cuales deben ser contextualizadas las políticas de vivienda. En Corea hay una intensa actividad inmobiliaria y la informalidad urbana, aunque existe, es mucho menor. En Colombia y Perú son marcados en los sistemas de vivienda la presencia de tres mercados (privado, público/ privado e informal), y la informalidad continúa siendo el principal canal de atención a la vivienda. En Colombia entre 1993-2005 la producción de vivienda informal fue del $65 \%$ y en Perú, en el 2011, de 133000 viviendas producidas anualmente un $70 \%$ eran informales (Piazza, 2011).

\section{Referencias}

Ambrosi, F. (2011). El banco de tierras: modelo de desarrollo urbano y habitacional en Colombia. En Mvcs Politicas para la generación de suelo urbano para vivienda de interés social. Lima: UNIAPRAVI.

Aramburú, R. (noviembre de 2016). Intervención en panel. Presentado en Conversatorio Problemática de la Vivienda en el Perú, Colegio de Arquitectos, Lima, Perú.

Bourdieu, P. (2002). Las estructuras sociales de la economía. Buenos Aires: Ed. Manantial.

Brenner, N., \& Theodore N. (2017). Las ciudades y las geografías del neoliberalismo realmente existente. En Brenner, N. Teoría urbana critica y politicas de escala. Barcelona: Icaria.

Burke, P. (1987). Sociología e historia. Madrid: Alianza Editorial.

Calderón, J. (2017). Housing policy and urban land Management. Comparative Approach in Korea, Colombia and Peru. En A. Blanco, M. Park, S. Lee, H. Lee \& F. Volpe Urban Renewal and Land Management. Experiences from territarias 40

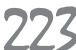


South Korea and Latin American (pp. 11-37). Washington: KRIHS-BID.

Calderón, J. (2016). La ciudad ilegal. Lima en el siglo XX. Lima: Punto Cardinal.

Calderón, J. (2015). Programas de vivienda social nueva y mercados de suelo urbano en el Perú. EURE 41(122), 27-48.

Calderón, J. (2013). Los pobres urbanos y la propiedad. Políticas y resultados. Madrid: Editorial Académica Española.

Calderón, J. (2009). El efecto Mivivienda: política de vivienda para la clase media y diferenciación social. Ecuador Debate, 76, 107-122.

Calderón, J. (1998). Mercado de tierras en áreas agrícolas periurbanas de Lima. Debate Agrario, 28, 1-22.

Camargo, A., \& Hurtado A. (2013). Urbanización informal en Bogotá: agentes y lógicas de producción del espacio urbano. INVI 28(78), 77-107.

Castillo, N. (3 de julio de 2014). El 59\% de la demanda de viviendas es por inmuebles de hasta US\$ 60 mil. El Comercio, página $\mathrm{B} 7$.

Cevallos, O. (2013). El problema de la vivienda, la renovación y la expansión urbana en Bogotá. En T. Bolívar \& J. Erazo Los lugares del hábitat y la inclusión (pp. 417-431). Quito: FLACSO.

Cevallos, O., \& Saldarriaga A. (2015). Vivienda y Estado en Colombia: 19181990. En Bolívar, T. M. Rodríguez \& J. Erazo Ciudades en Construcción Permanente ¿Destino de casas para todos? (pp. 93-123). Quito: Abya Yala- UCVCLACSO.
Cuervo, N., \& Jaramillo S. (2009). Dos décadas de politica de vivienda en Bogotá apostando por el Mercado. Bogotá: Universidad de Los Andes.

Cuellar, J. (2012). El desarrollo industrial en Corea del Sur (1960-2010). Elementos explicativos y de politica. Un contrapunto a la experiencia colombiana. (Tesis de Maestría, Universidad Nacional de Colombia, Bogotá).

Chang H. (2004). Retirar la escalera: la estrategia del desarrollo en perspectiva histórica. Madrid: La Catarata.

Duhau, E. (1998). Hábitat popular y politica urbana. México: UAM-A.

Fique, L. (2006). Vivienda social en Colombia. Politicas públicas y habitabilidad en los años noventa. Bogotá: UNC.

Henao, L. (2013). La política de vivienda social en Colombia. En MVCS-UNIAPRAVI Ciudad, vivienda social y suelo urbano (pp. 31-45). Lima: MVCS.

Hidalgo, R, Santana D., \& Alvarado V. (2016). Mitos, ideologías y utopías neoliberales en la producción del espacio. En R. Hidalgo, D. Santana, V. Alvarado, F. Arenas, A. Salazar, C. Valdebenito \& L. Álvarez En las costas del neoliberalismo. Naturaleza, urbanización y producción inmobiliaria en experiencias de Chile y Argentina (pp. 24-66). Santiago: PUCH.

Jung, H. (2014). New Town \& Land Development Policy in Korea. Gyeonggi-do: KRIHS-IDB.

Jung, H. \& Gi-Seon K. (2013). Manual of Implementing Land Adquisition and Resettlements for Urban Development of 
Korea for Developing Countries. Gyeonggi-do: KRIHS-GDPC.

Kahatt, S. (2015). Utopias construidas. Las unidades vecinales de Lima. Lima: PUCP.

Kemeny, J. (1992). Housing and social theory. London: Routledge.

Kemeny, J., \& Lowe, S. (1998). Schools of comparative Housing Research: From Convergence to Divergence. Housing Studies, 138(2), 161-176. Doi: https:// doi.org//10.1080/02673039883380

Kim, H. (2013). Land development and management. Gyeonggi-do: KRIHS-GDPC.

Kim, J. (s. f.). Public policies for new towns in Korea: an appraisal. Gyeonggi-do: KHRIS.

Kim, K. (2014). Managing the unmanageable: Seoul's experience of urban transformation. Seoul: Global Lab on Metropolitan Strategie Planning.

Kim, S. (2014). Belated but grand? The future of public housing in Korea. City, Culture and Society 5, 97-105.

La Grange, A., \& Jung H. (2013). Liberalization, Democratization and Korea's housing welfare regime. International Journal of Housing Policy, 13, 66-89.

La Grange, A. \& Jung H. (2004). The Commodification of Land and Housing: The Case of South Korea. Housing Studies, 10(4), 557-580.

Ludeña, W. (2004). Lima, historia y urbanismo en cifras. 1821-1970. Lima: MVCS-UNI.

Maldonado M., \& Hurtado A. (2013). La declaratoria de desarrollo y construcción prioritarios (sujeta a venta forzosa en pública subasta) en Colombia: la experien- cia de Bogotá 2008-2012. Cambridge: Lincoln Institute.

Maldonado, M. (2012). Limitaciones de las políticas de suelo y vivienda social para superar la exclusión social. La experiencia de Bogotá. En C. Salazar Irregular. Suelo y Mercado en América Latina (pp. 159-212). México: El Colegio de México.

Maldonado, M. (2005). Operación urbanistica Nuevo Usme: provisión de suelo urbanizado para vivienda social, a partir de la redistribución social de plusvalías. Bogotá: LILP-CIDER.

MDE, Ministerio de Desarrollo Económico Colombia (1996). Ciudades y ciudadania. La politica urbana del Salto Social. Bogotá: INURBE.

Ministerio de Vivienda del Perú (1980). Memoria, 1969-1979. Lima: MVC.

Moreno, R., \& González J. (2011). Macroproyectos de interés social nacional (MISN): Ciudad Verde. En MVCS - UNIAPRAVI Politicas para la generación de suelo urbano para vivienda de interés social (pp. 227-251). Lima: MVCS.

MVCs Ministerio de Vivienda, Construcción y Saneamiento del Perú (2014). Situación de los Barrios Urbano Marginales en el Perú 2012, Lima: MVCS.

MVCS Ministerio de Vivienda, Construcción y Saneamiento del Perú (2012). Manual del Programa de Generación de Suelo Urbano. Lima: MVCS.

Park, M. (2013). Housing Policy. A Primer on Korean Planning and Policy. Gyeonggido: KRIHS GDPC. 
Piazza, W. (2011). Retos en la construcción de vivienda social en el Perú. Políticas para la generación de suelo urbano para vivienda de interés social. Lima: MVCS.

Pinilla, J. (2013). Anuncio de Proyecto y avalúos de referencia como mecanismos de control a los precios del suelo: Estudio de caso operación estratégica Nuevo Usme, Bogotá Colombia”. Cambridge: Lincoln Institute.

Rojas, M., \& Rave B. (2014). Reajuste de tierras en Medellin, Colombia. Cambridge: Lincoln Institute.

Romero, M. (mayo de 2012). Politica de vivienda y desarrollo urbano y rural. Presentado en el Encuentro Vivienda, Suelo y Ciudad, Lima, Perú.

Smolka. M., \& Furtado F. (2014). Instrumentos notables de politicas de suelo en América Latina. Quito: Lincoln Institute.
Stephens, M (2014). Comparative housing research: a "system-embedded" approach. Meaning and measurement in comparative housing research, (pp. 2544) London: Routledge.

Stiglitz, J. (1997). Algunas enseñanzas del milagro del Este asiático. Desarrollo Económico 7 (147), 323-349.

Su Jin L. (2015). República de Corea: Reforma Agraria, Guerra y modernización. En J. L. Angel (ed.) Los vínculos Corea del Sur - México. Historia, politica y economía (pp. 77-98). Colima: Universidad de Colima.

Torres, C. (marzo de 2008). Suelo urbano y vivienda social en Bogotá: Primacía del mercado y el sacrificio del interés general, 1990-2007. Ponencia presentada en el VII Seminario Nacional de Investigación Urbano Regional, Universidad Nacional de Colombia (UNC), Medellín, Colombia. 